Check for updates

Cite this: Chem. Sci., 2019, 10, 9017

๑ All publication charges for this article have been paid for by the Royal Society of Chemistry

Received 24th June 2019

Accepted 31st July 2019

DOI: $10.1039 / c 9 s c 03115 d$

rsc.li/chemical-science

\section{Selective access to either a doubly boron-doped tetrabenzopentacene or an oxadiborepin from the same precursor $\dagger$}

\author{
Julian Radtke, ${ }^{a}$ Kai Schickedanz, ${ }^{a}$ Marcel Bamberg, ${ }^{a}$ Luigi Menduti, (DD ${ }^{a}$ \\ Dieter Schollmeyer, ${ }^{b}$ Michael Bolte, (DD ${ }^{a}$ Hans-Wolfram Lerner (iD) ${ }^{a}$ \\ and Matthias Wagner (D)*a
}

\begin{abstract}
The well-known red emitter tetrabenzo[de,hi,op,st]pentacene (TBPA) has been transformed into a bright blue emitter ( $\mathrm{B}_{2}$-TBPA; $\lambda_{\mathrm{em}}=472 \mathrm{~nm}$; $\mathrm{c}$-hexane) via substitutional doping with two boron atoms. In contrast to the electron-rich TBPA, which forms endo-peroxides with $\mathrm{O}_{2}$ under daylight, the benchtopstable $\mathrm{B}_{2}$-TBPA is a good electron acceptor and undergoes reversible reduction at a moderate half-wave potential of $E_{1 / 2}=-1.73 \mathrm{~V}$ (vs. $\mathrm{FcH} / \mathrm{FcH}{ }^{+} ; \mathrm{THF}$ ). Although the size of $\mathrm{B}_{2}$-TBPA falls within the nanoscale, the helically twisted compound readily dissolves in c-hexane and does not require solubilizing substituents. The synthesis of $B_{2}$-TBPA is based on the nickel-mediated Yamamoto-type dehalogenation of tetrabrominated 9,10-di(naphth-1-yl)-9,10-dihydro-9,10-diboraanthracene. This intramolecular C-C heterocoupling reaction shows a remarkable solvent dependence: $\mathrm{B}_{2}$-TBPA forms only in pyridine $79 \%$ yield), whereas an oxadiborepin is obtained from THF solutions (ODBE, 81\%; the reaction mixture is quenched with air in both cases). Insight into the corresponding reaction mechanism was gained from the isolation of intermediates and an investigation of their chemical properties. ODBE is an interesting blue emitter in its own right. Furthermore, it can be ring-opened with excess $\mathrm{BBr}_{3}$ at the $\mathrm{B}-\mathrm{O}-\mathrm{B}$ moiety to afford a dimeric borabenzo[de]anthracene.
\end{abstract}

\section{Introduction}

Polycyclic aromatic hydrocarbons (PAHs) are ubiquitous building blocks for organic optoelectronic materials. ${ }^{1}$ Tuning of their frontier orbital energies, and, in turn, their light absorption/emission characteristics or redox properties, can be achieved by varying the degree of annulation, the edge structure, and the pattern of peripheral substituents. ${ }^{2} \mathrm{~A}$ fourth powerful tool - arguably the synthetically most challenging one - is substitutional doping, i.e., the replacement of selected $\mathrm{C}\left(\mathrm{sp}^{2}\right)$ atoms within the PAH scaffold by other p-block atoms. ${ }^{3}$ Among those, boron is a particularly useful electronically perturbative element, as it renders the resulting B-PAHs electron deficient and moderately Lewis acidic. ${ }^{4}$

A fruitful strategy by which to obtain a deeper understanding of structure-property relationships in B-PAHs and to identify

\footnotetext{
anstitut für Anorganische Chemie, Goethe-Universität Frankfurt, Max-von-Laue-Strasse 7, D-60438 Frankfurt (Main), Germany. E-mail: matthias. wagner@chemie.uni-frankfurt.de

${ }^{b}$ Institute of Organic Chemistry, Johannes Gutenberg University Mainz, Duesbergweg 10-14, D-55128 Mainz, Germany

$\dagger$ Electronic supplementary information (ESI) available: CCDC 1922188-1922192. For ESI and crystallographic data in CIF or other electronic format see DOI: $10.1039 / \mathrm{c} 9 \operatorname{sc} 03115 \mathrm{~d}$
}

promising new lead structures is to compare PAHs of proven applicability directly with their B-doped counterparts. Given that $\mathrm{B}$ atom possesses one valence electron less than a $\mathrm{C}$ atom, the transition from a stable closed-shell PAH to a closed-shell B$\mathrm{PAH}$ requires the incorporation of an even number of $\mathrm{B}$ atoms. Examples include doubly B-doped acenes, ${ }^{5}$ pyrene, ${ }^{6}$ perylene, ${ }^{7-9}$ or bisanthene. ${ }^{10}$

The bottom-up preparation of even larger structures, in the size regime of nanographene flakes, becomes increasingly difficult, mainly because of solubility issues and a lack of broadly applicable synthetic protocols. These problems can be illustrated by considering Yamaguchi's approach to the diborateranthene derivative III (Chart 1): ${ }^{11}$ Initial attempts to assemble the teranthene framework via oxidative cyclodehydrogenation of Bcontaining tri(9,10-anthrylene)s such as I (intramolecular Scholl reaction $^{12}$ ) gave inseparable mixtures of unidentified products. ${ }^{13,14}$ The introduction of $o, p$-directing mesityloxy substituents $^{15}$ at both 9-anthryl moieties resulted in an activation of four of the eight relevant C-H groups (exc $\mathrm{FeCl}_{3}$ in a $\mathrm{CH}_{3} \mathrm{NO}_{2} / \mathrm{CH}_{2} \mathrm{Cl}_{2}$ solvent mixture). However, chlorination rather than cyclization took place ( $c f$. II). ${ }^{16}$ Only when four peripheral MesO groups and two extra annulated $o$-phenylene rings were simultaneously present at the anthryl fragments and the heterocyclic core, respectively, did the Scholl reaction proceed smoothly to afford the fully cyclized III. The purple-colored compound absorbs in 
the entire visible range of the electromagnetic spectrum and shows weak fluorescence across the visible/near-IR region. ${ }^{11}$ Remarkable turn-on fluorescence was observed upon exposure of III to various Lewis bases, among them $\mathrm{NH}_{3}$, indicating a potential use of this B-PAH as gas-sensor material. ${ }^{17}$ Moreover, prototype Li-ion batteries containing derivatives of III as electrodes have been fabricated. In this context, a conflict between the requirement for solubilizing side chains during the synthesis and purification of III and the obstructive impact of these substituents on the device performance emerged: large MesO groups led to a leaking of the electrode material into the battery electrolyte and decreased the specific capacity of the battery. Smaller $n$-BuO substituents resulted in lower yields of the B-PAH, because its poor solubility in common organic solvents made the purification procedure more laborious. ${ }^{17}$ Similar problems occur when organic light-emitting devices (OLEDs) or organic fieldeffect transistors (OFETs) are to be fabricated, because large, dangling substituents prevent tight packing of the materials in the solid state and thus reduce the extent of $\pi-\pi$ interactions between the molecules.

Given this background, we decided to develop alternative routes to access soluble, benchtop-stable, nanoscale B-PAHs. The aim is to maintain the remarkable and useful properties of compounds such as III, but to have more possibilities for derivatization $^{\mathbf{1 8}}$ and avoid solubilizing or kinetically protecting substituents. In the new compounds, the two B atoms should still constitute integral parts of the PAH scaffold such that structural constraint ${ }^{19,20}$ protects them from adduct formation with $\mathrm{O}_{2} / \mathrm{H}_{2} \mathrm{O}$ and further shielding with bulky substituents is not required. A positive effect on the solubility of the B-PAH should be brought about by inducing a helical twist ${ }^{21}$ rather than by adding organyl substituents ( $c f$. the hexane-soluble [4] helicene $\mathbf{I V}^{\mathbf{2 2}} v s$. the planar B-PAH V; ${ }^{, 23,24}$ Chart 1). As Scholl-type oxidative dehydrogenation reactions are usually associated with forcing conditions, milder and more selective reductive dehalogenation protocols, such as the Yamamoto reaction, ${ }^{25,26}$ will be applied ( $c f$. our syntheses of $\mathbf{I V}^{\mathbf{2 2}}$ and related twisted borepins ${ }^{\mathbf{1 8}}$ ). As our specific target molecule, we selected compound $\mathbf{B}_{2}$-TBPA (Chart 1), a doubly B-doped congener of tetrabenzo[de,hi,op,st]pentacene (TBPA; $c f$. Chart 2). Pentacenes, in general, are among the most important compounds for organic electronics, ${ }^{27,28}$ and TBPA, in particular, has already been employed as a red emitter in OLEDs ${ }^{29,30}$ and also as an OFET material. ${ }^{31-33}$ Furthermore, TBPA has a low ionization potential $^{34,35}$ and the two $\mathrm{C}$ atoms located at the cusps of both cove regions $^{36}$ accumulate the largest HOMO electron density. ${ }^{37}$ B-Doping at these positions, as in the case of $\mathbf{B}_{2}$-TBPA, is therefore expected to have a profound influence on the optoelectronic properties of the molecule. Apart from being a pentacene derivative, $\mathbf{B}_{2}$-TBPA can be viewed as consisting of two diboraperylenes sharing the central $\mathrm{B}_{2} \mathrm{C}_{4}$ ring (Chart 2). $\mathbf{B}_{2}$-TBPA also contains two fragments resembling the [4]helicene $\mathbf{I V}$, which has already proven its suitability as an emitter in a B-PAH-based OLED device. ${ }^{38,39}$ Last but not least, the $\mathrm{B}$ atoms formally divide the large $\pi$ system of $\mathbf{B}_{2}$-TBPA into two smaller $\pi$ systems of type $\mathbf{V}$.

Herein, we report a high-yield synthesis of $\mathbf{B}_{\mathbf{2}}$-TBPA, starting from readily available tetrahalogenated 9,10-di(naphth-1-yl)9,10-dihydro-9,10-diboraanthracene precursors, by adapting

\section{Wagner 2012}<smiles></smiles>

I
Yamaguchi 2013<smiles></smiles>

| this work

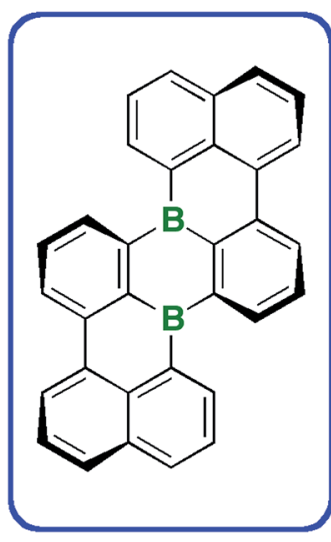

$\mathbf{B}_{2}$-TBPA

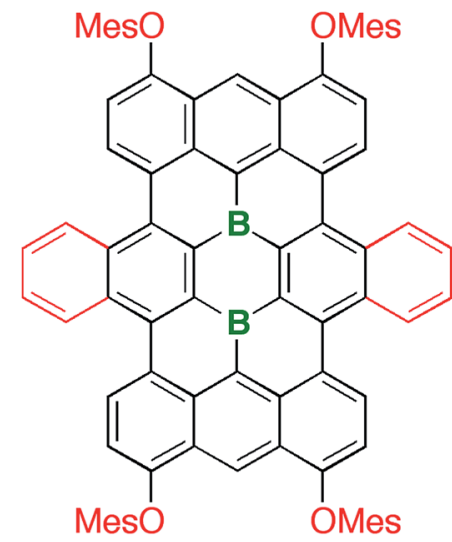

III

\section{Wagner 2015 Hatakeyama 2015}

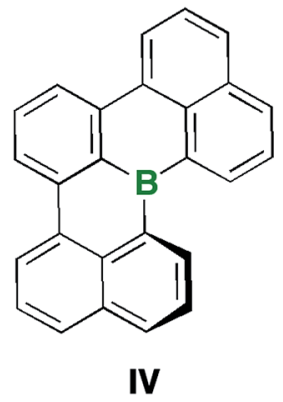

Wagner 2015

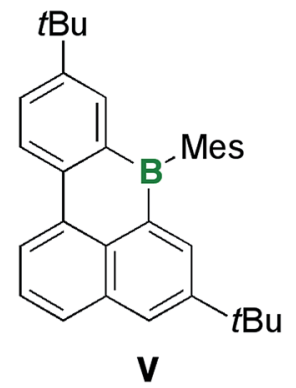

Chart 1 Previously reported examples of B-doped PAHs (Mes = mesityl).

the Yamamoto protocol. We also disclose the surprising result that a simple change of solvent from pyridine to THF changes the major product from $\mathbf{B}_{2}$-TBPA to an oxadiborepin ODBE (the 
<smiles>B1c2cccc3c2B(c2cccc4cccc1c24)c1cccc2cccc-3c12</smiles>

pentacene<smiles>B1c2cccc3c2B(c2cccc4cccc1c24)c1cccc2cccc-3c12</smiles>

[4]helicene

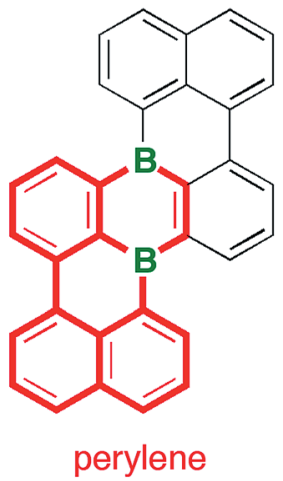<smiles>B1c2cccc3c2B(c2cccc4cccc1c24)c1cccc2cccc-3c12</smiles>

borabenzo[de]anthracene
Chart 2 Substructures included in $\mathrm{B}_{2}$-TBPA.

reaction mixture is quenched with air in both cases). A mechanistic scenario rationalizing the underlying rearrangement reaction is proposed. Finally, we discuss key optoelectronic properties of $\mathbf{B}_{2}$-TBPA and ODBE in comparison to those of the reference systems TBPA, IV, and $\mathbf{V}$.

\section{Results and discussion}

\section{Syntheses}

For the synthesis of the B-doped multiple helicene $\mathbf{B}_{2}$-TBPA, we started from the tetrahalogenated 9,10-dihydro-9,10diboraanthracene (DBA) derivatives $\mathbf{1}^{\mathbf{x}}$, which are readily available from the corresponding known borinic acids and 6 equiv. of $\mathrm{BBr}_{3}$ (Scheme 1; cf. the ESI for full details). ${ }^{40}$ Treatment of $\mathbf{1}^{\mathbf{x}}$ with 2 equiv. of (8-halogenonaphth-1-yl)lithium ${ }^{41,42}$ furnished syn/anti-isomer mixtures of $2^{\mathbf{X}, \mathbf{Y}}$ in yields between $60 \%\left(2^{\mathbf{F}, \mathbf{B r}}\right)$ and $89 \%\left(2^{\mathbf{B r}, \mathbf{I}}\right)$. The compounds are benchtop-stable and can be purified by column chromatography; a separation of syn/anti$2^{\mathbf{X}, \mathbf{Y}}$, however, was not possible.

Our first attempt at forming the last two $\mathrm{C}-\mathrm{C}$ bonds on the way from $2^{\mathbf{X}, \mathbf{Y}}$ to $\mathbf{B}_{2}$-TBPA relied on an $\mathrm{Li} / \mathrm{I}$ exchange at the naphthyl substituents of $\mathbf{2}^{\mathbf{F}, \mathbf{I}}$ and a subsequent intramolecular nucleophilic attack at the two $\mathrm{C}-\mathrm{F}$ functionalities. Reactions of this type are well established for various fluoroarenes. ${ }^{44,45}$ In the particular case of $\mathbf{2}^{\mathbf{F}, \mathbf{I}}$, the cyclization reaction should be facilitated by the fact that the $\mathrm{B}-\mathrm{C}=\mathrm{C}-\mathrm{F}$ fragment is a Michael-type system.

However, $2^{\mathbf{F}, \mathbf{I}}$ proved largely inert toward stoichiometric quantities of $n$-BuLi (2 equiv., $\mathrm{Et}_{2} \mathrm{O},-78{ }^{\circ} \mathrm{C}$ to $\mathrm{rt}, 16 \mathrm{~h} ; 83 \%$ of a)<smiles>[Y]c1cccc([Y])c1B1c2c([Y])cccc2B(c2cccc3cccc([Y])c23)c2c([Y])ccc([Y])c21</smiles>

$$
\begin{aligned}
& 1^{\mathrm{F}}: \mathrm{X}=\mathrm{F} \\
& 1^{\mathrm{Br}}: \mathrm{X}=\mathrm{Br}
\end{aligned}
$$

$$
\begin{aligned}
& 2^{\mathrm{F}, \mathrm{Br}}: \mathrm{X}=\mathrm{F}, \quad \mathrm{Y}=\mathrm{Br} \\
& \mathbf{2}^{\mathrm{F}, \mathrm{I}}: \mathrm{X}=\mathrm{F}, \mathrm{Y}=\mathrm{I} \\
& \mathbf{2}^{\mathrm{Br}, \mathrm{Br}}: \mathrm{X}=\mathrm{Br}, \mathrm{Y}=\mathrm{Br} \\
& \mathbf{2}^{\mathrm{Br}, \mathrm{I}}: \mathrm{X}=\mathrm{Br}, \mathrm{Y}=\mathrm{I}
\end{aligned}
$$
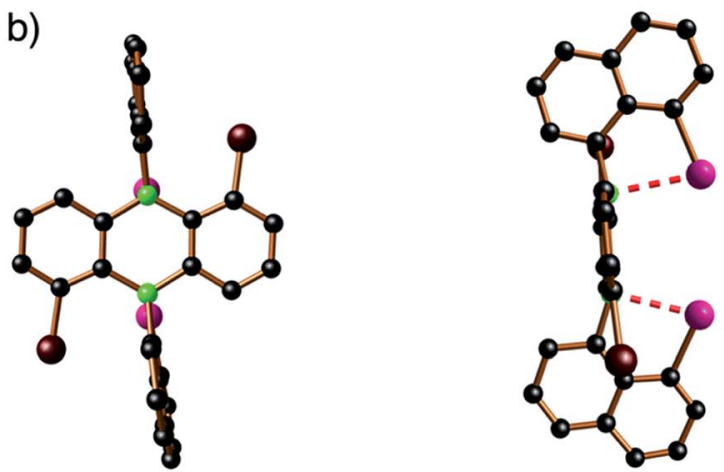

Scheme 1 (a) Synthesis of the 9,10-bis(8-halogenonaphth-1-yl)-DBAs $2^{\mathrm{X}, \mathrm{Y}}$. (b) Structure of syn- $2^{\mathrm{Br}, \mathrm{I}}$ in the solid state (C atoms: black, B atoms: green, $\mathrm{Br}$ atoms: brown, I atoms: purple; $\mathrm{H}$ atoms omitted for clarity). ${ }^{43}$ Reagents and conditions: (i) 2 equiv. of (8-halogenonaphth-1-yl)lithium, $\mathrm{Et}_{2} \mathrm{O}, \mathrm{O}^{\circ} \mathrm{C}$ to rt.

$2^{\mathbf{F}, \mathbf{I}}$ re-isolated), but underwent complete degradation in the presence of excess lithiating reagent (4 equiv., $\mathrm{Et}_{2} \mathrm{O},-78{ }^{\circ} \mathrm{C}$ to rt, $16 \mathrm{~h} ; 74 \%$ of naphthalene isolated). A similar reaction outcome was observed for $2^{\mathbf{F}, \mathbf{B r}}$. Therefore, we modified the approach and treated $\mathbf{1}^{\mathbf{F}}$ directly with 2 equiv. of 1,8-dilithionaphthalene. A complex reaction mixture was obtained from which the B-doped [4] helicene IV (Chart 1) was isolated in a yield of $11 \%$. Even though the presence of $\mathrm{C}(\mathrm{Ph})-\mathrm{C}(\mathrm{Naph})$ bonds in IV indicates that the desired nucleophilic substitution of $\mathrm{F}$ substituents is possible in principle, the lack of a selective conversion demanded a fundamentally different synthetic strategy for $\mathbf{B}_{2}$-TBPA.

We next focused on $2^{\mathrm{Br}, \mathbf{B r}} / \mathbf{2}^{\mathrm{Br}, \mathrm{I}}$ and the Yamamoto-type C-Ccoupling protocol that had successfully been applied to the targeted preparation of $\mathbf{I V}\left(1\right.$ equiv. of $\left[\mathrm{Ni}(\mathrm{COD})_{2}\right] / \mathrm{bpy} / \mathrm{COD}$ per $\mathrm{C}-\mathrm{Br}$ unit, $\mathrm{rt}$, high dilution; $\mathrm{COD}=1,5$-cyclooctadiene, $\mathrm{bpy}=$ $2,2^{\prime}$-bipyridyl). ${ }^{22}$ The formation of paramagnetic Ni species in the course of the reaction precluded the NMR-spectroscopic monitoring of its progress. Thus, we routinely quenched the reaction mixtures after approximately $20 \mathrm{~h}$ by bubbling air through the vessel to precipitate all Ni-containing compounds 
(attempts at a workup under inert conditions were unsuccessful; $c f$. the ESI $\uparrow$ for more details).

After filtration, the filtrates were free of paramagnetic impurities and suitable for NMR-spectroscopic investigations: $\mathbf{2}^{\mathbf{B r}, \mathbf{B r}}$ or $\mathbf{2}^{\mathbf{B r}, \mathbf{I}}$ were reproducibly converted to only one major product; however, the nature of this product depended heavily on the choice of solvent (Scheme 2). THF solutions, which are common media for Yamamoto reactions, ${ }^{46,47}$ contained ODBE instead of the multiple helicene $\mathbf{B}_{2}$-TBPA after quenching. The two $\mathrm{C}(\mathrm{Ph})-\mathrm{C}(\mathrm{Naph})$ bonds in ODBE point toward successful debromination/C-C coupling, but the reaction also involved the formation of a third $\mathrm{C}-\mathrm{C}$ bond and the cleavage of two $\mathrm{B}-\mathrm{C}$ bonds. After replacement of THF with pyridine, an atypical solvent for Yamamoto-type transformations, $\mathbf{B}_{2}$-TBPA was isolated in high yields, whereas ODBE was not detected.

ODBE can be regarded as the intramolecular anhydride of two borinic acid moieties. Therefore, we explored the possibility of opening the ring through hydrolysis of the B-O-B bridge and, indeed, observed the emergence of an additional set of signals in the in situ ${ }^{1} \mathrm{H}$-NMR spectrum $\left(\mathrm{CDCl}_{3}\right.$ and two drops of added $\mathrm{H}_{2} \mathrm{O}$; NMR tube, rt; $c f$. Fig. S3-46†). The number of these signals was the same as in the case of ODBE, but the chemical shift values differed slightly. After some time, the integral ratio of both sets of signals remained constant, which can be explained by assuming a dynamic equilibrium between ODBE and its open-chain hydrolysis product. In an attempt to cleave the B-O-B link quantitatively, we next treated ODBE with 5 equiv. of $\mathrm{BBr}_{3}\left(\mathrm{CDCl}_{3}\right.$; sealed NMR tube, $\left.140{ }^{\circ} \mathrm{C}, 2 \mathrm{~d}\right)$. This time, the signals of ODBE completely vanished and new signals assignable to the ditopic bromoborane 3 appeared (Scheme 3; $c f$. the

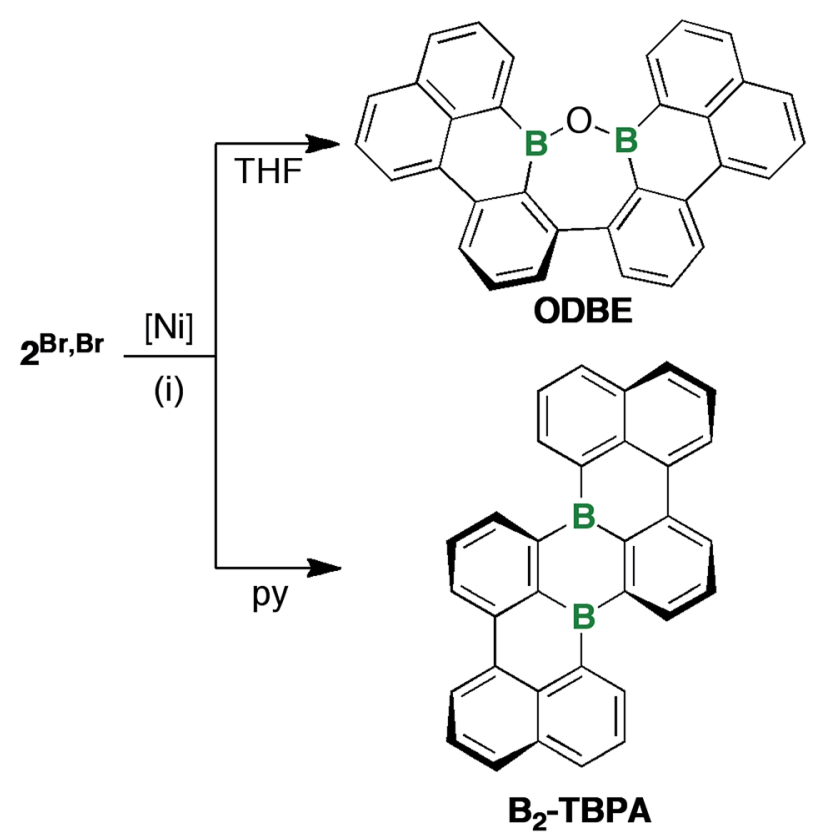

Scheme 2 Synthesis of ODBE (in THF) and $\mathrm{B}_{2}$-TBPA (in pyridine) starting from $2^{\mathrm{Br}, \mathrm{Br}}$. Reagents and conditions: (i) 4 equiv. of $\left[\mathrm{Ni}(\mathrm{COD})_{2}\right] /$ bpy/COD, rt, high dilution; COD $=1,5$-cyclooctadiene, bpy $=2,2^{\prime}$ bipyridyl, py = pyridine.
$\mathrm{ESI} \uparrow$ for the NMR data); the addition of $\mathrm{H}_{2} \mathrm{O}$ quantitatively reverted 3 to ODBE.

\section{NMR-spectroscopic and X-ray crystallographic characterization of $2^{\mathrm{X}, \mathrm{Y}}, \mathrm{B}_{2}$-TBPA, and ODBE}

Each of the four derivatives $2^{\mathbf{X}, \mathbf{Y}}$ gives rise to two similar sets of resonances in the ${ }^{1} \mathrm{H}$ - as well as the ${ }^{13} \mathrm{C}\left\{{ }^{1} \mathrm{H}\right\}$-NMR spectrum. All of these signals can be assigned to tetrahalogenated 9,10bis(naphth-1-yl)-DBAs in which both phenylene halves and both naphthyl substituents are related by symmetry. Compounds $2^{\mathbf{X}, \mathbf{Y}}$ thus exist as mixtures of $s y n$ - and anti-isomers, which do not interconvert due to restricted rotation about the exocyclic B-C bonds. ${ }^{14}$ One of these isomers (likely $\left.s y n\right)^{43}$ dominates by a factor of 10 in the sterically most encumbered $2^{\mathbf{B r}, \mathbf{I}}$ and by a factor of 2 in the second most congested derivative $2^{\mathbf{B r}, \mathbf{B r}}$. Samples of $2^{\mathbf{F}, \mathbf{B r}}$ or $\mathbf{2}^{\mathbf{F}, \mathbf{I}}$ contain the syn- and anti-isomers in essentially equimolar distributions.

The ${ }^{11} \mathrm{~B}\left\{{ }^{1} \mathrm{H}\right\}$-NMR spectra of $\mathbf{2}^{\mathbf{X}, \mathbf{Y}}$ are characterized by broad resonances with chemical shift values between 50 and $54 \mathrm{ppm}$. The ${ }^{11} \mathrm{~B}$ nuclei are therefore shielded by approximately $20 \mathrm{ppm}$ compared to those of 9,10-bis(2-methylnaphth-1-yl)-DBA (71 ppm). ${ }^{14}$ This shielding effect likely results from (weak) intramolecular $\mathrm{B} \cdots \mathrm{Y}$ adduct bonds, ${ }^{16}$ which are also indicated by $\mathrm{X}$ ray diffraction analysis of $2^{\mathrm{Br}, \mathbf{I}}$. Scheme $1 \mathrm{~b}$ shows the solid-state structure of $s y n-2^{\mathrm{Br}, \mathbf{I}} \cdot{ }^{43}$ Its B $\cdots$ I contacts of 2.78(1) and 2.82(1) are more than $1 \AA$ shorter than the sum of the corresponding van der Waals radii $(3.90 \AA)^{48}$ and both boron centers are slightly pyramidalized $\left(\Sigma(\mathrm{C}-\mathrm{B}-\mathrm{C})=354.7\right.$ and $\left.356.7^{\circ}\right)$.

The successful dehalogenative cyclization to furnish $\mathbf{B}_{2}$-TBPA is evidenced by the following findings: (i) instead of the two signal sets characteristic of syn/anti-2 ${ }^{\mathbf{B r}, \mathbf{B r}}$, only one set of resonances remains in the ${ }^{1} \mathrm{H}$ - as well as ${ }^{13} \mathrm{C}\left\{{ }^{1} \mathrm{H}\right\}$-NMR spectrum of $\mathbf{B}_{2}$-TBPA (this finding is also in line with the very low inversion barrier expected for the two planar-chiral [4] helicene fragments, ${ }^{49,50}$ which should otherwise give a pair of diastereomers); (ii) the numbers of ${ }^{1} \mathrm{H}$ - and ${ }^{13} \mathrm{C}$-NMR signals are only compatible with a highly symmetric structure, thereby ruling out the possibility of just one $\mathrm{C}-\mathrm{C}$-coupling event; (iii) $\mathrm{Br}-\mathrm{C}$ (ipso) resonances of syn/anti-2 ${ }^{\mathbf{B r}, \mathbf{B r}}$ at 135.2 and $126.8 \mathrm{ppm}$ are absent in the ${ }^{13} \mathrm{C}\left\{{ }^{1} \mathrm{H}\right\}$ NMR spectrum of $\mathbf{B}_{\mathbf{2}}$-TBPA, whereas downfield-shifted signals at

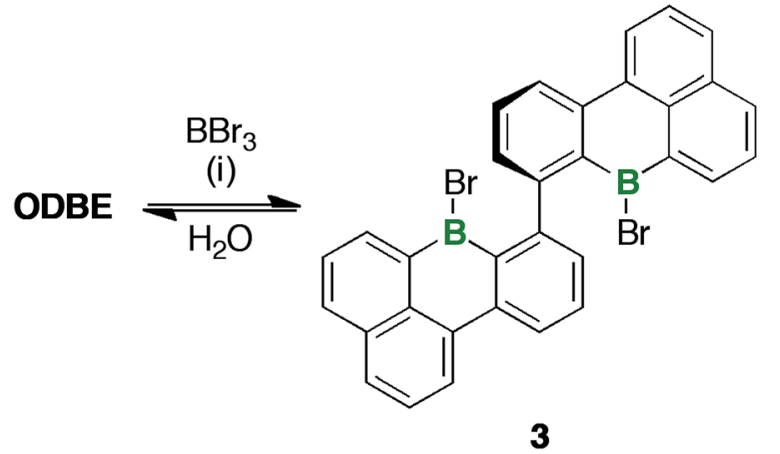

Scheme 3 Synthesis of 3 through treatment of ODBE with $\mathrm{BBr}_{3}$. Reagents and conditions: (i) 5 equiv. of $\mathrm{BBr}_{3}, \mathrm{CDCl}_{3}, 140{ }^{\circ} \mathrm{C}, 2 \mathrm{~d}$. 
140.5 and $132.7 \mathrm{ppm}$ are present (assignable to the quaternary carbon atoms at the newly formed $\mathrm{C}-\mathrm{C}$ bonds).

The molecular structure of $\mathbf{B}_{2}$-TBPA was confirmed by X-ray crystallography (Fig. 1b). B $\mathbf{B}_{2}$-TBPA possesses $C_{2}$ symmetry and two different kinds of axial chiral units: a cylindrical spiral substructure with its symmetry-related congener of the same helicity $^{51}$ ( $c f$. the blue screw axes) and one helical pentacene ribbon ( $c f$. the red screw axis). ${ }^{52}$ Starting from the aromatic ring containing $\mathrm{C}(15)$, the five annulated rings contribute absolute values of $3.8(4), 12.4(3), 17.8(5), 12.4(3)$, and $3.8(4)^{\circ}$ to the overall absolute twist of $50.2(5)^{\circ} .{ }^{53}$ The solid-state structures of $\mathbf{B}_{2}$-TBPA and TBPA are very much alike, apart from two significant differences: the end-to-end twist in the carbonaceous TBPA $\left(40.9^{\circ} \text {; Fig. 1a) }\right)^{54}$ is less pronounced by almost $10^{\circ}$, which proves benzene rings to be more rigid than their $\mathrm{B}$ doped counterparts. In a similar vein, the $\mathrm{B}-\mathrm{C}$ bond lengths of $\mathbf{B}_{2}$-TBPA (1.540(6)-1.572(7) $\AA$ ) are markedly longer than the corresponding C-C bonds of TBPA (1.404(5)-1.480(5) Å). The [4] helicene fragments of $\mathbf{B}_{\mathbf{2}}$-TBPA and TBPA show essentially the same degree of distortion (skew angle between the $\mathrm{C}(1)$ - a)
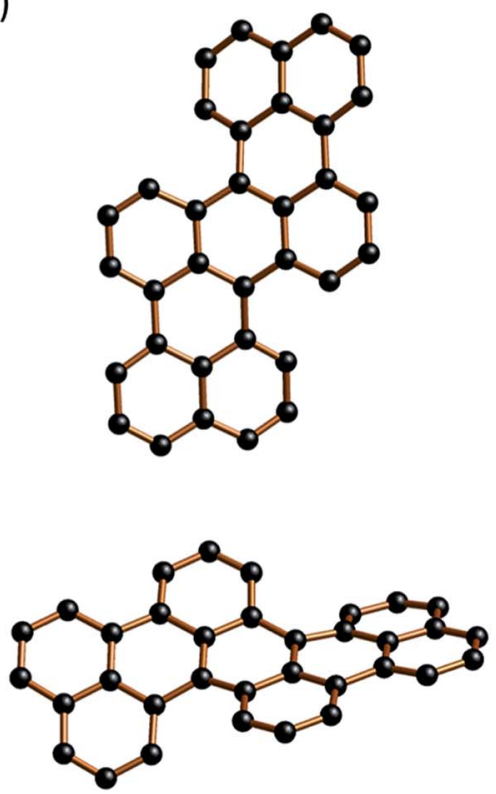

b)
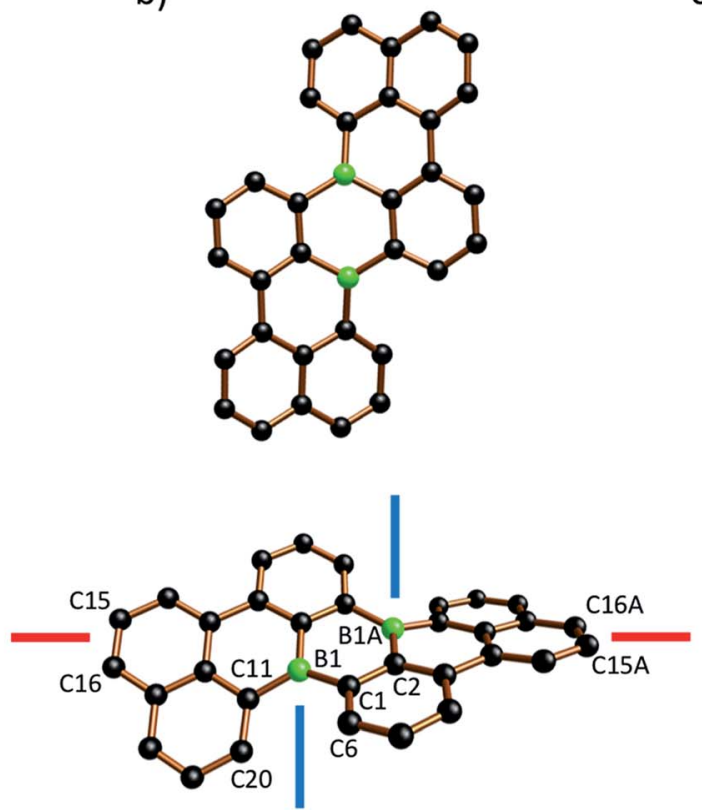

c)
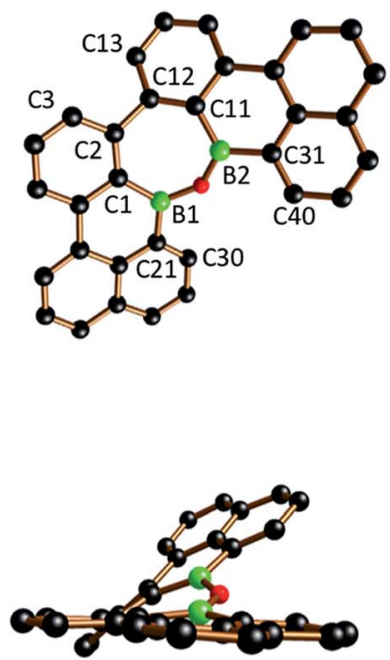

Fig. 1 Two views of the crystallographically determined molecular structures of TBPA (a; CCDC 1216750, ref. 54), $B_{2}$-TBPA (b), and ODBE (c) in the solid state ( $\mathrm{C}$ atoms: black, $\mathrm{B}$ atoms: green, $\mathrm{O}$ atoms: red; $\mathrm{H}$ atoms omitted for clarity). Selected bond lengths $(\AA)$, bond angle $\left({ }^{\circ}\right)$, and torsion angles/skew angle between vectors $\left(^{\circ}\right)$ : $B_{2}$-TBPA: $B(1)-C(1)=1.572(7), B(1)-C(11)=1.548(6), B(1)-C(2 A)=1.540(6) ; C(6)-C(1)-C(11)-C(20)=$ 38.0. ODBE: $B(1)-C(1)=1.567(13), B(1)-C(21)=1.458(16), B(1)-O(1)=1.418(13), B(2)-C(11)=1.496(15), B(2)-C(31)=1.564(14), B(2)-O(1)=$ 1.382(14); $B(1)-O(1)-B(2)=134.8(10) ; C(30)-C(21)-C(31)-C(40)=33.3(10), C(1)-B(1)-B(2)-C(11)=25.0(10), C(3)-C(2)-C(12)-C(13)=37.4(16)$.

Table 1 Photophysical and electrochemical data of $B_{2}-T B P A, T B P A, I V, V$, and ODBE

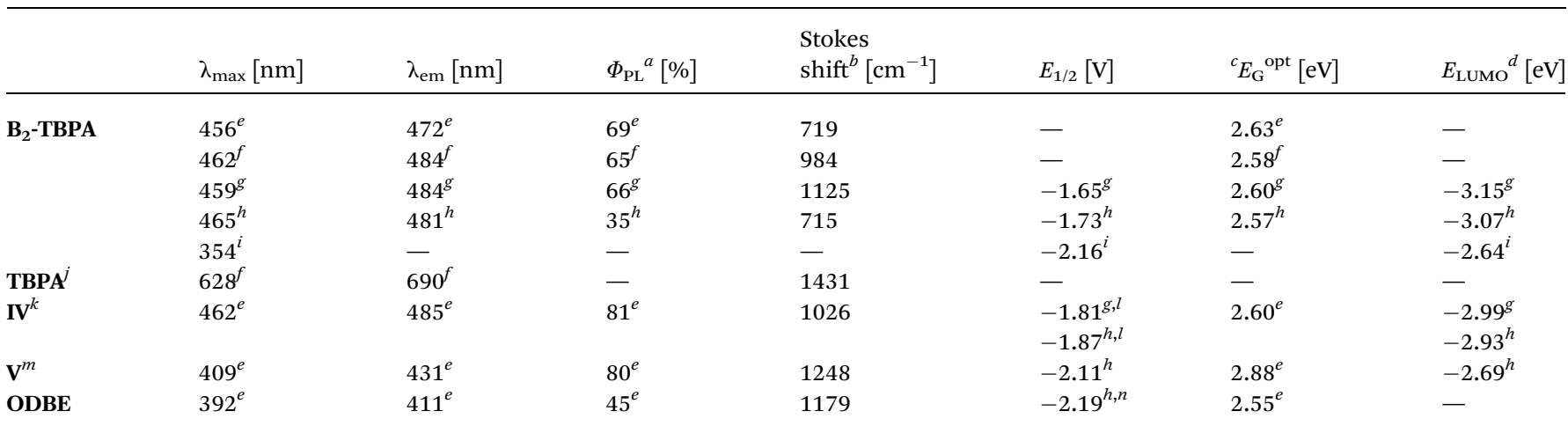

${ }^{a}$ Quantum yields were determined using a calibrated integrating sphere. ${ }^{b}$ Stokes shifts represent the difference between each longest wavelength absorption maximum and the corresponding shortest wavelength emission maximum. ${ }^{c}$ Optical band gap $E_{\mathrm{G}}{ }^{\mathrm{opt}}=1240 / \lambda_{\mathrm{onset}} \cdot \lambda_{\text {onset }}$ was determined by constructing a tangent on the point of inflection of the bathochromic slope of the most red-shifted absorption maximum. ${ }^{d} E_{\mathrm{LUMO}}=-4.8 \mathrm{eV}-E_{1 / 2}{ }^{\mathrm{Red} 1}\left(\mathrm{FcH} / \mathrm{FcH}^{+}=-4.8 \mathrm{eV}\right.$ vs. vacuum level). ${ }^{e} c$-Hexane. ${ }^{f} \mathrm{C}_{6} \mathrm{H}_{6} .{ }^{g} \mathrm{CH}_{2} \mathrm{Cl}_{2} .{ }^{h}$ THF. ${ }^{i}$ Pyridine. ${ }^{j}$ Ref. $30 .{ }^{k}$ Ref. $22 .{ }^{l}$ Our measurements. ${ }^{m}$ Ref. $23 .{ }^{n} E_{\mathrm{pc}}$ value of an irreversible reduction event. 
$\mathrm{C}(6)$ and $\mathrm{C}(11)-\mathrm{C}(20)$ vectors $=38.0^{\circ}$ and $39.4^{\circ}$, respectively). Monohelicene IV is remarkably less twisted $\left(21.0^{\circ}\right),{ }^{22,38}$ which leads to the conclusion that the two helical units present in $\mathbf{B}_{\mathbf{2}^{-}}$ TBPA (and TBPA) reinforce each other.

The central benzene ring of TBPA is deformed to a boat conformation with an average flip angle of $14.9^{\circ}$ between the bow/stern and the plane defined by the other four $\mathrm{C}$ atoms. It has been suggested that this deformation governs the reactivity of TBPA toward the electrophilic $\mathrm{O}_{2}$ molecule, ${ }^{54}$ which, under daylight, forms an endo-peroxide connecting the bow/stern $\mathrm{C}$ atoms. ${ }^{37}$ The $\mathrm{B}_{2} \mathrm{C}_{4}$ core of the boron isoster $\mathbf{B}_{2}$-TBPA also adopts a boat conformation, such that it should similarly be possible to bridge the $\mathrm{B}$ atoms at the bow/stern by a diatomic unit (flip angle $=17.1^{\circ}$ ). Given that $\mathbf{B}_{2}$-TBPA is isoelectronic with the $\mathbf{T B P A}^{2+}$ dication, suitable reaction partners would be ditopic Lewis bases, rather than electrophiles ( $c f$. the triptycene-type adducts between DBA and 1,2-diacenes) ${ }^{55,56}$ Despite numerous efforts, we did not succeed in the crystallization of corresponding tricyclic scaffolds from $\mathbf{B}_{\mathbf{2}}$-TBPA/phthalazine mixtures, even though titration experiments using DMAP showed $\mathbf{B}_{2}$-TBPA to possess considerable Lewis acidity (see below).

The ${ }^{1} \mathrm{H}$ - and ${ }^{13} \mathrm{C}\left\{{ }^{1} \mathrm{H}\right\}$-NMR spectra of $\mathbf{B}_{2}$-TBPA and ODBE are deceptively similar. Yet, differences became apparent for the chemical shift values of the $\mathrm{C}-\mathrm{H}$ vectors pointing into the cove regions of $\mathbf{B}_{2}$-TBPA and ending up in bay and gulf regions ${ }^{36}$ of ODBE. As a consequence of $\pi$-donation from the $\mathrm{O}$ bridge, the $\mathrm{B}$ nuclei of ODBE are more shielded by $13 \mathrm{ppm}$ than those of $\mathbf{B}_{\mathbf{2}^{-}}$ TBPA $\left(\delta\left({ }^{11} \mathrm{~B}\right)=43\right.$ vs. $\left.56 \mathrm{ppm}\right)$.

The solid-state structure of ODBE adopts $C_{1}$ symmetry (Fig. 1c). The two B atoms are not directly attached to each other but linked through an $\mathrm{O}$ atom to afford a seven-membered oxadiborepin heterocycle. The B-O bond lengths amount to 1.382(14)/1.418(13) $\AA$ and the B-O-B bond angle is $134.8(10)^{\circ}$. ODBE differs significantly from planarity with absolute torsion angles of $\mathrm{C}(30)-\mathrm{C}(21)-$ $\mathrm{C}(31)-\mathrm{C}(40)=33.3(10)^{\circ}$ (gulf twist), $\mathrm{C}(1)-\mathrm{B}(1)-\mathrm{B}(2)-\mathrm{C}(11)=$ $25.0(10)^{\circ}$ (endocyclic twist), and $\mathrm{C}(3)-\mathrm{C}(2)-\mathrm{C}(12)-\mathrm{C}(13)=37.4(16)^{\circ}$ (bay twist). A doubly benzannulated oxadiborepin model system, i.e., the intramolecular anhydride of 2,2'-bis(dihydroxyboryl)-1,1'biphenyl, shows an even higher gulf $\left(46.1(3)^{\circ}\right)$ and endocyclic twist $\left(39.6(2)^{\circ}\right)$, whereas the bay twist remains largely the same $\left(36.6(2)^{\circ}\right) .^{57,58}$ If the two annulated benzene rings of the model system are replaced with five-membered thiophene rings in a way that places the sulfur atoms at the opening of the bay region, the resulting oxadiborepin relaxes to a largely planar conformation. ${ }^{59}$

To assess the qualities of ODBE as a potentially ditopic Lewis acid, we grew crystals from an equimolar ODBE/phthalazine mixture. A $1: 1$ adduct was obtained, in which, however, the phthalazine molecule acts only as monodentate $\mathrm{N}$ ligand $(\mathrm{B}(1)-$ $\mathrm{N}(1)=1.686(14) \AA, \mathrm{B}(2) \cdots \mathrm{N}(2)=2.945(15) \AA$; see the ESI for more details $\dagger$ ).

\section{Optoelectronic properties of $\mathbf{B}_{2}$-TBPA and ODBE}

The doubly B-doped tetrabenzo[de,hi,op,st $]$ pentacene $\mathbf{B}_{2}$-TBPA and the oxadiborepin ODBE have been investigated by cyclic voltammetry (THF, $\left[n-\mathrm{Bu}_{4} \mathrm{~N}\right]\left[\mathrm{PF}_{6}\right], 0.1 \mathrm{M}, 200 \mathrm{mV} \mathrm{s}{ }^{-1}$, vs. $\mathrm{FcH} /$ $\mathrm{FcH}^{+}$). While the carbonaceous TBPA is electron-rich, ${ }^{34} \mathbf{B}_{2}$-TBPA undergoes a reversible one-electron reduction at a moderately cathodic half-wave potential of $E_{1 / 2}=-1.73 \mathrm{~V}$ (Table 1). Electron injection into the reference compounds IV or $\mathbf{V}$ (Chart 1) requires more cathodic half-wave potentials of $E_{1 / 2}=-1.87$ (our measurement) and $-2.11 \mathrm{~V}^{23}$ respectively (Table 1 ). The differences between the monoboranes IV/V and $\mathbf{B}_{2}$-TBPA reflect the impact of the second electron-deficient $\mathrm{B}$ atom as is further corroborated by the increasingly cathodic $E_{1 / 2}\left(\mathbf{B}_{2}\right.$-TBPA) values in solvents of increasing Lewis basicities: -1.65 $\left(\mathrm{CH}_{2} \mathrm{Cl}_{2}\right)<$ -1.73 (THF) $<-2.16 \mathrm{~V}$ (pyridine). As outlined below, $\mathbf{B}_{2}$-TBPA tends to form monoadducts with pyridine donors, which basically eliminates the contribution of the tetracoordinate B atom to $\pi$-electron delocalization and renders the redox potential of

a)

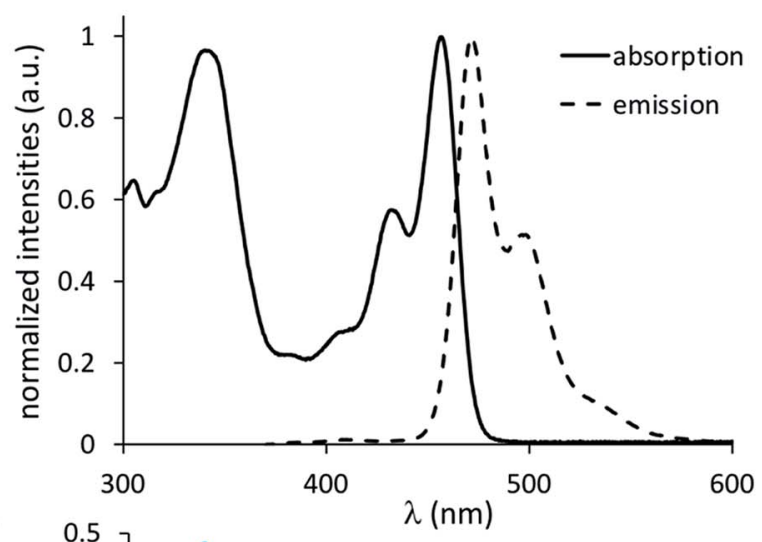

b)
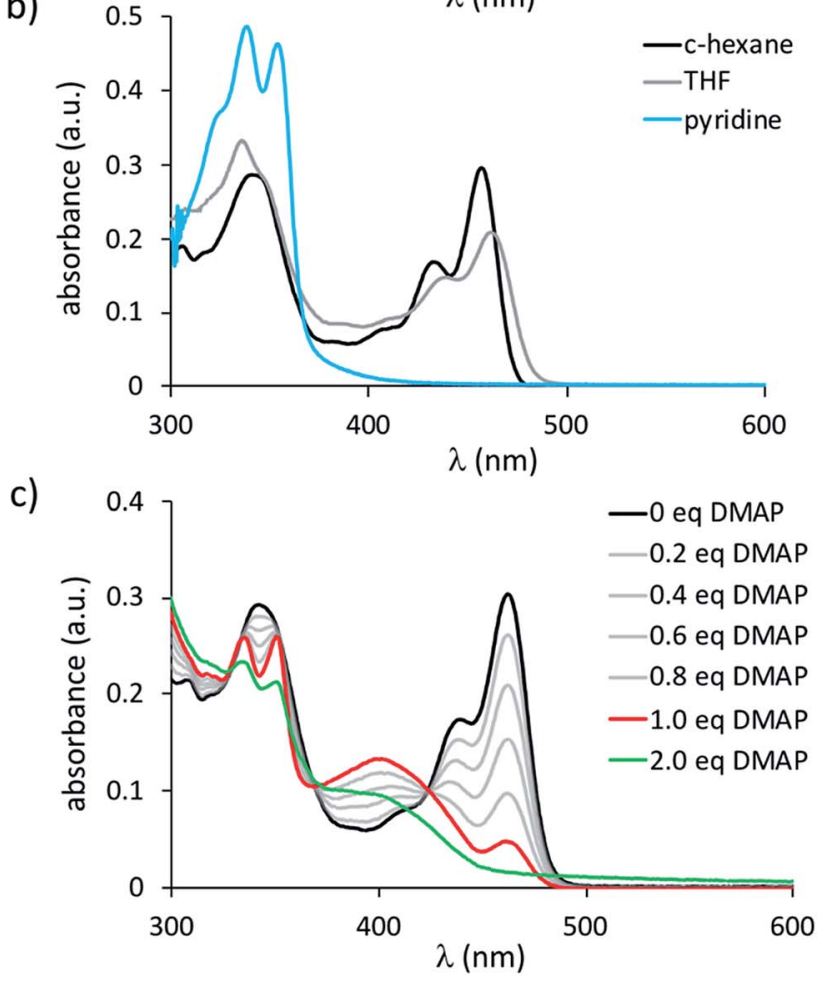

Fig. 2 (a) Normalized UV-vis absorption and emission spectra of $B_{2}$ TBPA in $c$-hexane. (b) UV-vis absorption spectra of $B_{2}$-TBPA in $C^{-}$ hexane, THF, and pyridine at the same concentration of $10^{-4} \mathrm{M}$. (c) UV-vis absorption spectra of $B_{2}$-TBPA in the presence of various amounts of 4-dimethylaminopyridine (DMAP) in $\mathrm{C}_{6} \mathrm{H}_{6}$ at the same concentration of $10^{-4} \mathrm{M}$. 
$\mathbf{B}_{2}$-TBPA pyridine similar to that of a borabenzo[de]anthracene moiety (Charts 1 and 2). Contrary to $\mathbf{B}_{2}$-TBPA, ODBE shows only one irreversible redox wave in its cyclic voltammogram, the cathodic peak potential of which is very similar to the half-wave potential of $\mathrm{V}\left(E_{\mathrm{pc}}=-2.19 \mathrm{~V}\right.$ vs. $\left.E_{1 / 2}=-2.11 \mathrm{~V}\right)$.

TBPA is a blue compound, showing red to near-infrared photoluminescence $\left(\lambda_{\max }=628 \mathrm{~nm}, \lambda_{\mathrm{em}}=690 \mathrm{~nm}\right.$ in $\mathrm{C}_{6} \mathrm{H}_{6}$; Table 1). ${ }^{30}$ Its analogue, $\mathbf{B}_{2}$-TBPA, in contrast, possesses a yellow color and emits in the blue region of the electromagnetic spectrum with an appreciable quantum efficiency of $\Phi_{\mathrm{PL}}=69 \%\left(\lambda_{\max }\right.$ $=456 \mathrm{~nm}, \lambda_{\mathrm{em}}=472 \mathrm{~nm}$ in c-hexane; Fig. 2a). In line with the rigid scaffold of $\mathbf{B}_{2}$-TBPA, its Stokes shift is small $\left(719 \mathrm{~cm}^{-1}\right)$ and the electronic spectra are vibrationally resolved. The absorption spectrum remains essentially the same upon going from $c$ hexane to $\mathrm{C}_{6} \mathrm{H}_{6}$ to $\mathrm{CH}_{2} \mathrm{Cl}_{2}$. This picture changes when donor solvents are used: in THF, the lower-energy band loses intensity with respect to the higher-energy band, and only the latter remains in pyridine (Fig. 2b). The solvatochromism of the fluorescence band in the solvent range from $c$-hexane to THF is also negligible $( \pm 10 \mathrm{~nm})$, whereas pyridine quenches the emission. These observations agree with the results obtained from cyclic voltammetry, which indicated that THF is not completely innocent toward $\mathbf{B}_{2}$-TBPA and that pyridine can act as a ligand. To shed more light on the properties of $\mathbf{B}_{2}$-TBPA as a Lewis acid, we performed a titration with 4-dimethylaminopyridine (DMAP; Fig. 2c). During the addition of 0.2-1.0 equiv. of DMAP, the absorption at $462 \mathrm{~nm}$ gradually became smaller, but did not completely vanish. A full quenching was achieved after the addition of approximately 2 equiv. of DMAP; apart from that, no further qualitative changes occurred and two isosbestic points at 328 and $370 \mathrm{~nm}$ are present in the entire range between 0 and 2 equiv. of added DMAP. Thus, $\mathbf{B}_{2}$-TBPA still behaves as a Lewis acid, but only monoadducts $\mathbf{B}_{2}$-TBPA $\cdot$ DMAP seem to be formed, even with the strong donor DMAP. A second series of titrations, using $\left[n-\mathrm{Bu}_{4} \mathrm{~N}\right] \mathrm{F}$ as the source of Lewis-basic $\mathrm{F}^{-}$ions, gave analogous results ( $c f$. the ESI $\dagger$ ).

A comparison of $\mathbf{B}_{2}$-TBPA with the reference systems IV and $\mathbf{V}$ reveals the [4]helicene to possess very similar absorption and emission characteristics, whereas both $\lambda_{\max }$ and $\lambda_{\text {em }}$ of the $7 \mathrm{H}$-7borabenzo[de]anthracene are hypsochromically shifted (Table 1). In particular, the differences between $\mathbf{B}_{\mathbf{2}}$-TBPA and $\mathbf{V}$ demonstrate that the two halves of $\mathbf{B}_{2}$-TBPA are electronically coupled to an appreciable degree. In contrast, ODBE absorbs and emits further to the blue than $\mathbf{B}_{\mathbf{2}}$-TBPA and even $\mathbf{V}$. This hypsochromic shift is likely due to the electron-donating effect of the oxygen atom, which increases the HOMO-LUMO energy difference of ODBE with respect to $\mathbf{B}_{2}$-TBPA ( $c f$. Table S6-5†). Furthermore, there is apparently little electronic communication across the $\mathrm{B}-\mathrm{O}-\mathrm{B}$ fragment or the twisted $\mathrm{C}-\mathrm{C}$ bond of ODBE.

\section{Mechanistic considerations}

As outlined above, the reaction between $\mathbf{1}^{\mathbf{F}}$ and 2 equiv. of 1,8dilithionaphthalene gave a complex product mixture, from which the B-doped [4] helicene IV was isolated in $11 \%$ yield.

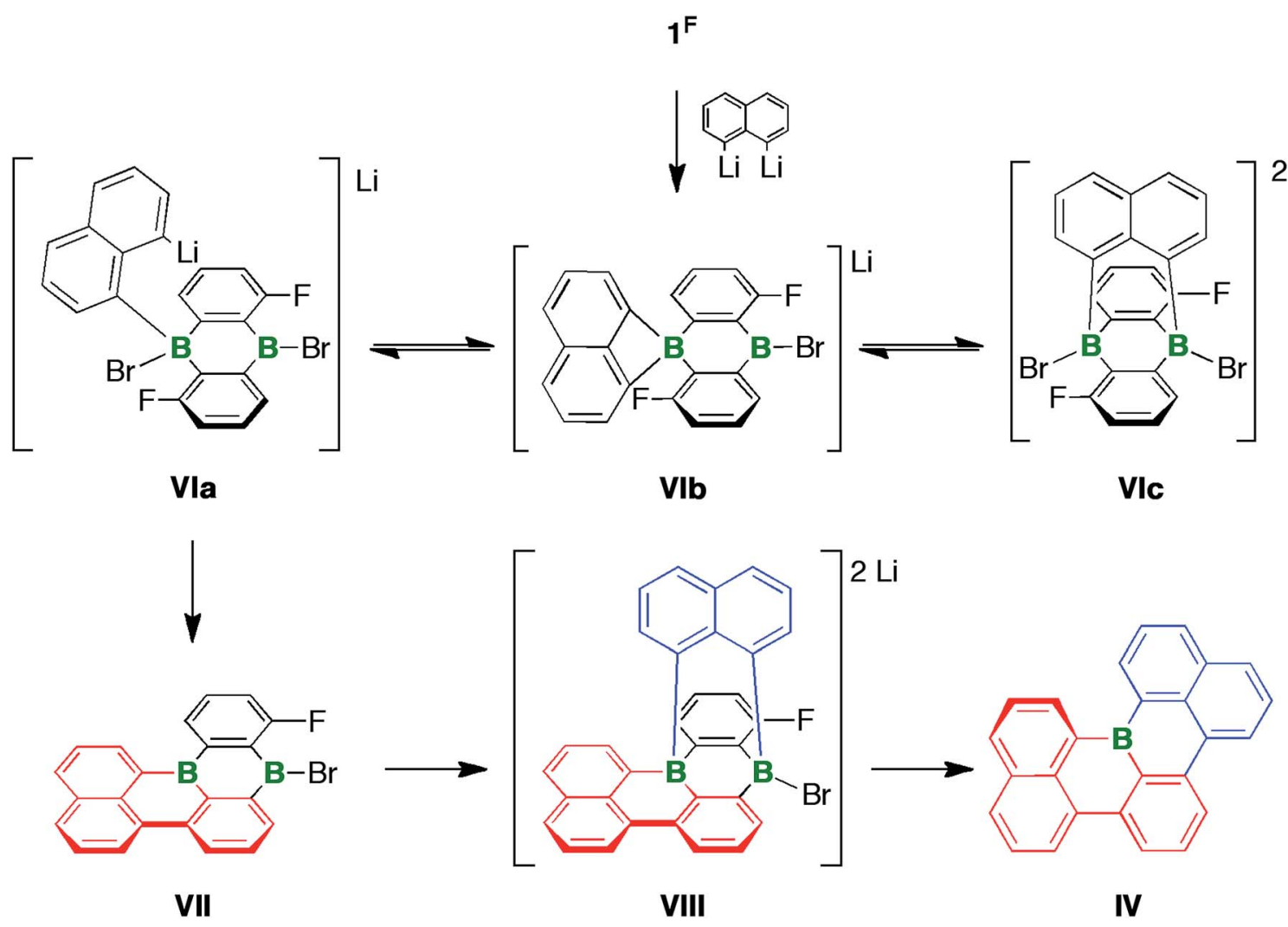

Scheme 4 Three modes of interaction (Vla-VIc) between 1,8-dilithionaphthalene and the ditopic Lewis acid $1^{\mathrm{F}}$. Formation of the [4]helicene IV via the proposed intermediates VII and VIII. 
Three interconvertible modes of interaction, all of which are potentially relevant for the formation of $\mathbf{I V}$, are conceivable between 1,8-dilithionaphthalene and the ditopic Lewis acid $\mathbf{1}^{\mathbf{F}}$ (Scheme 4): the ligand can bind in a monodentate fashion such that one C-Li functionality remains uncoordinated (VIa), or in a chelating mode to create a four-membered $\mathrm{BC}_{3}$ ring (VIb), or in a $\mathrm{B} \cdots \mathrm{B}$-bridging manner to furnish a tricyclic, triptycene-type system (VIc). Precedence for the proposed structural motifs of VIb and VIc exists in the form of the dimesityl-1,8naphthalenediylborate anion $\mathbf{6 0}^{\mathbf{6 0 1}}$ and several diacene- or carboxylate-bridged DBAs ${ }^{55,56,62}$ that have been crystallographically characterized. The adduct VIa could undergo LiBr elimination and $\mathrm{C}-\mathrm{F}$ substitution to afford the intermediate VII, which adds a second equivalent of 1,8-dilithionaphthalene to give the tricyclic compound VIII with two tetracoordinate $\mathrm{B}$ centers. It has recently been disclosed that certain DBA-based tetraarylborates are prone to reductive elimination with formation of biaryls and formal extrusion of diarylboryl anions (which subsequently stabilize themselves through intra- or intermolecular insertion reactions). ${ }^{63}$ A similar scenario involving the B atom ortho to the F substituent would establish the required $\mathrm{C}-\mathrm{C}$ bond between the red and blue fragments. Subsequent cleavage of the only remaining exocyclic B-C bond (at the latest during chromatographic workup) opens a way to IV.

The Yamamoto-coupling reaction of $2^{\mathbf{B r}, \mathbf{B r}}$ is remarkably solvent dependent, as it selectively leads to either $\mathbf{B}_{2}$-TBPA or ODBE when carried out in pyridine or THF, respectively. The mechanistic pathways underlying these transformations are difficult to elucidate, because even elementary steps of $\mathrm{Ni}$ mediated Yamamoto-coupling reactions are still subject to debate and strongly influenced by the nature of the substrate and the choice of solvent. ${ }^{64}$ Originally, Semmelhack proposed two sequential oxidative addition steps, ultimately leading from one mononuclear $\left[\mathrm{Ni}^{0}\right]$ complex and two aryl halides $\mathrm{Ar}-\mathrm{X}$ to species of the form $\left[\mathrm{Ar}_{2} \mathrm{Ni}^{\mathrm{IV}} \mathrm{X}_{2}\right]$; subsequent reductive elimination gives the desired biaryl $\mathrm{Ar}-\mathrm{Ar}$ and $\left[\mathrm{Ni}^{\mathrm{II}} \mathrm{X}_{2}\right]$ (in DMF) ${ }^{65}$ Tsou and Kochi suggested a $\left[\mathrm{Ni}^{\mathrm{I}}\right] /\left[\mathrm{Ni}^{\mathrm{III}}\right]$ radical-chain scenario for the coupling process (mainly in nonpolar solvents). ${ }^{66,67}$ Specifically for the cases of [(bpy) Ni(COD)]-mediated Ar-X coupling reactions, Yamamoto identified complexes [(bpy) $\left.\mathrm{Ni}^{\mathrm{II}}(\mathrm{X}) \mathrm{Ar}\right]$ as primary intermediates, which dismutate in the ratedetermining step via dinuclear aggregates to give [(bpy) $\left.\mathrm{Ni}^{\mathrm{II}} \mathrm{Ar}_{2}\right]$ and $\left[(\mathrm{bpy}) \mathrm{Ni}^{\mathrm{II}} \mathrm{X}_{2}\right]$. Reductive elimination from $\left[(\mathrm{bpy}) \mathrm{Ni}^{\mathrm{II}} \mathrm{Ar}_{2}\right]$ then regenerates 1 equiv. of [(bpy) $\left.\mathrm{Ni}^{0}\right]$ and produces $\mathrm{Ar}-\mathrm{Ar}$ (in DMF $){ }^{25}$ None of these scenarios, however, accounts for empirical observations made by us and others, ${ }^{\mathbf{1 8 , 2 2 , 6 8 - 7 0}}$ namely, that the addition of excess COD ligand and of 2 equiv. rather than 1 equiv. of $\left[\mathrm{Ni}(\mathrm{COD})_{2}\right] /$ bpy per $\mathrm{C}-\mathrm{C}$ bond to be formed results in improved yields of the Ar-Ar coupling products. We currently believe that one of the benefits of using more than the stoichiometrically required amount of $\left[\mathrm{Ni}(\mathrm{COD})_{2}\right] /$ bpy traces back to the intramolecular nature of the cyclization reaction: according to Yamamoto's ligand metathesis mechanism, two Ni atoms have to insert at the same time into both $\mathrm{C}-\mathrm{Br}$ bonds involved in dehalocoupling. An increase in the amount of available $\left[\mathrm{Ni}^{0}\right]$ species will increase the chance that this prerequisite is fulfilled.

Irrespective of the general ambiguities regarding the mechanistic details of the Yamamoto reaction, we have succeeded in shedding light on some essential aspects of our transformations:

(i) $\mathbf{B}_{2}$-TBPA and ODBE result from rare Yamamoto-type heterocoupling reactions. Nevertheless, they proceed in high yields and we found no indications for competing intra- or intermolecular homocoupling.

(ii) $\mathbf{B}_{2}$-TBPA (in pyridine) or ODBE (in THF) are not only accessible from $2^{\mathbf{B r}, \mathbf{B r}}$ and 4 equiv. of $\left[\mathrm{Ni}(\mathrm{COD})_{2}\right] / \mathrm{bpy} / \mathrm{COD}$, but also from the monocyclized derivative 4 (Scheme 5) and 2 equiv. of the Yamamoto reagent (under otherwise identical reaction conditions).

(iii) In pyridine, $\left[\mathrm{Ni}(\mathrm{COD})_{2}\right] / \mathrm{bpy} / \mathrm{COD}$ (4 equiv.) leaves $\mathbf{B}_{2^{-}}$ TBPA unaffected. From THF, a complex product mixture devoid of ODBE was obtained after the usual workup process.

a)

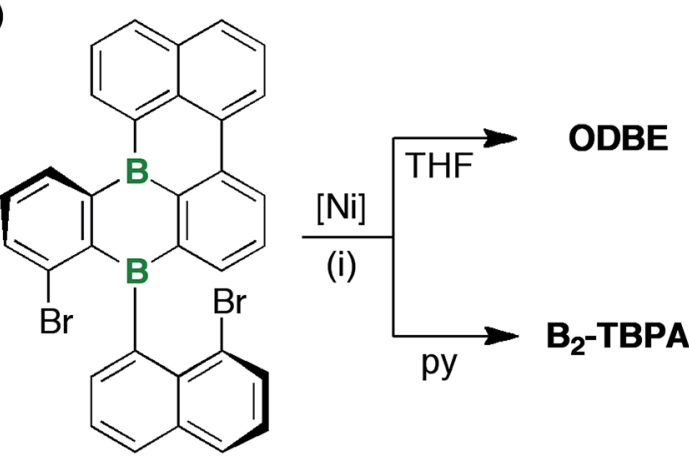

4

b)

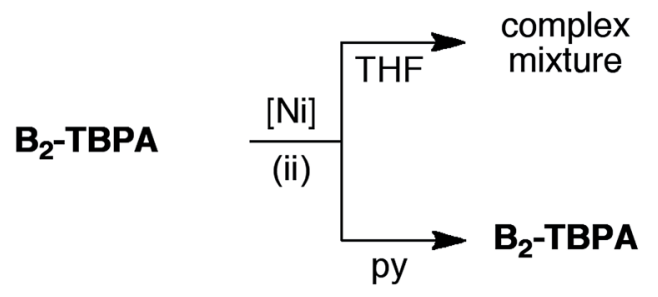

c)

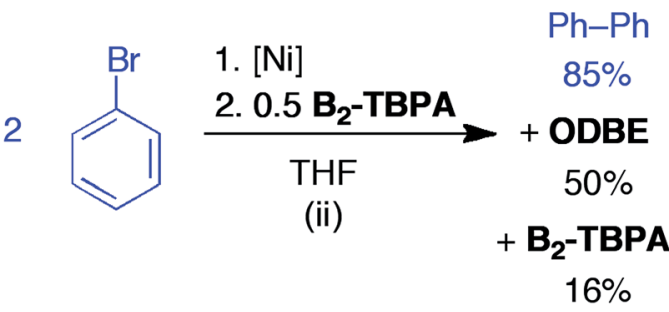

Scheme 5 (a) Synthesis of ODBE (in THF) and $B_{2}$-TBPA (in pyridine) starting from 4. (b) Different behavior of $B_{2}$-TBPA toward the Yamamoto reagent in THF vs. pyridine. (c) Transformation of $B_{2}$-TBPA to ODBE with "spent Yamamoto reagent" and quenching with air. Reagents and conditions: (i) 2 equiv. of $\left[\mathrm{Ni}(\mathrm{COD})_{2}\right] / \mathrm{bpy} / \mathrm{COD}$. (ii) 4 equiv. of $\left[\mathrm{Ni}(\mathrm{COD})_{2}\right] / \mathrm{bpy} / \mathrm{COD}$ per $\mathrm{B}_{2}$-TBPA. $\mathrm{COD}=1,5$-cyclooctadiene, bpy $=2,2^{\prime}$ - bipyridyl, py $=$ pyridine 
<smiles></smiles>

IX<smiles>c1cc2c3c(c1)-c1cccc4c1-c1cccc5cccc(c15)B2OB3c1cccc2cccc-4c12</smiles>

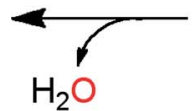

ODBE

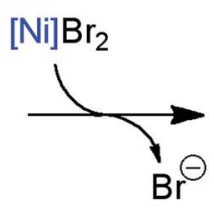<smiles>OB1c2c(B3c4c(Br)cccc4-c4cccc5cccc3c45)cccc2-c2cccc3cccc1c23</smiles>

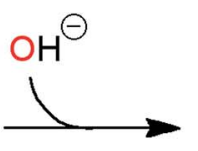<smiles>OB1C(Br)=C2C=CC=C(c3c4cccc3C(=CC=C4)[B-]2(O)c2cccc3cccc([N]Br)c23)c2cccc3cccc1c23</smiles><smiles>OB1C2=CC=Cc3cccc2c3-c2cccc(-c3cccc4c3B(O)c3cccc5cccc-4c35)c21</smiles>

(iv) A "spent Yamamoto reagent", prepared via homocoupling of 2 equiv. of $\mathrm{Ph}-\mathrm{Br}$ with 2 equiv. of [ $\left.\mathrm{Ni}(\mathrm{COD})_{2}\right] / \mathrm{bpy} / \mathrm{COD}$ in THF, transformed 0.5 equiv. of added $\mathbf{B}_{2}$-TBPA to ODBE in $50 \%$ yield (after quenching; yield of re-isolated $\mathbf{B}_{2}$-TBPA: $16 \%$, yield of biphenyl: $85 \%$ ).

The results (ii)-(iv) do not exclude that the DBA rearrangement occurring in THF can already be initiated at the stages of $2^{\mathbf{B r}, \mathbf{B r}}$ or 4 . Yet, as unequivocally demonstrated by experiment (iv), we can most easily explain all observations by assuming that $\mathbf{B}_{2}$-TBPA is formed as the primary product in both solvents, but only in THF is it further converted to ODBE. This conversion is promoted by the "spent Yamamoto reagent" and uses the $\mathrm{O}_{2} /$ $\mathrm{H}_{2} \mathrm{O}$ from the quenching step as oxygen sources (recall that solutions of $\mathbf{B}_{2}$-TBPA alone are benchtop-stable). ${ }^{71}$

Taking all available information together, we arrive at the following working hypothesis regarding the $\mathbf{B}_{2}$-TBPA $\rightarrow$ ODBE rearrangement: the overall process, which requires the cleavage of two juxtaposed B-C bonds and connects the resulting borabenzo[de]anthracene halves via both previously B-bonded C atoms, starts with the coordination of $\mathrm{OH}^{-}$to one $\mathrm{B}$ atom (Scheme 6 ; $c f$. the $\mathrm{F}^{-}$titration of $\mathbf{B}_{2}$-TBPA). The corresponding adduct $\mathbf{I X}$ is an active transmetalating reagent and shifts the phenyl ligand onto the $\left[(\mathrm{bpy}) \mathrm{NiBr}_{2}\right]$ present in the "spent Yamamoto reagent". The repetition of this process at the second B atom ultimately leads to the diaryl nickel species
$\mathbf{X}$ (Scheme 6). A subsequent reductive elimination from $\mathbf{X}$ establishes the new $\mathrm{C}-\mathrm{C}$ bond. Intramolecular condensation of the ditopic borinic acid according to Scheme 3 ultimately furnishes the oxadiborepin ODBE.

Why is this reaction sequence suppressed in pyridine? In view of the DMAP-titration results, it is conceivable that pyridine coordination to boron prevents (or at least delays) the attack of $\mathrm{OH}^{-}$ions. In case that single-electron transfer processes contribute to the rearrangement reaction, it is also important to recall that $\mathbf{B}_{2}$-TBPA is harder to reduce by $430 \mathrm{mV}$ in pyridine vs. THF solutions. As a third option, reactive $\mathrm{Ni}$ species may be tamed if pyridine is present as a strong ligand.

\section{Conclusions}

We have shown that a mild intramolecular C-C-heterocoupling reaction of the Yamamoto type is an ideal tool for the synthesis of nanoscale doubly B-doped polycyclic aromatic hydrocarbons, such as the tetrabenzopentacene derivative $\mathbf{B}_{2}$-TBPA. However, special care must be taken to choose the proper solvent: the otherwise identical synthesis protocol produces high yields of $\mathbf{B}_{2}$-TBPA when the reaction is carried out in pyridine, whereas in THF solution, the oxadiborepin ODBE is formed almost quantitatively. Mechanistic investigations revealed an oxidative rearrangement $\mathbf{B}_{2}$-TBPA $\rightarrow$ ODBE, taking place in THF during the $\mathrm{O}_{2} / \mathrm{H}_{2} \mathrm{O}$ quench, as the most straightforward explanation. As 
THF solutions of $\mathbf{B}_{2}$-TBPA are inert toward air and moisture, the rearrangement reaction is obviously promoted by nickel species present in the "spent Yamamoto reagent". We assume that pyridine suppresses the formation of ODBE because of its ligand properties, which annihilate the residual Lewis acidity of $\mathbf{B}_{2}$-TBPA and also tame the nickel complexes.

With regard to the materials properties of carbonaceous TBPA $v s$. $\mathbf{B}_{2}$-TBPA, the most notable effects of boron doping are a shift in the emission wavelengths from red to blue and a change in the redox behavior from electron-donating to electron-accepting. Similar to $\mathbf{B}_{2}$-TBPA, ODBE is a benchtopstable blue fluorophore, but possesses a lower electron affinity, due to its $\pi$-donating oxygen atom.

\section{Conflicts of interest}

There are no conflicts to declare.

\section{Acknowledgements}

This work was partially funded by the Bundesministerium für Wirtschaft und Energie through the WIPANO grant number 03THW10F04. Donations of lithium organyls by Albemarle Lithium $\mathrm{GmbH}$ are gratefully acknowledged.

\section{Notes and references}

1 (a) C. Wang, H. Dong, W. Hu, Y. Liu and D. Zhu, Chem. Rev., 2012, 112, 2208-2267; (b) A. Facchetti, Chem. Mater., 2011, 23, 733-758; (c) J. E. Anthony, Angew. Chem., Int. Ed., 2008, 47, 452-483; (d) J. Wu, W. Pisula and K. Müllen, Chem. Rev., 2007, 107, 718-747; (e) R. G. Harvey, Policyclic Aromatic Hydrocarbons, Wiley and Sons, New York, 1997.

2 R. Rieger and K. Müllen, J. Phys. Org. Chem., 2010, 23, 315325.

3 Main Group Strategies towards Functional Hybrid Materials, ed. T. Baumgartner and F. Jaekle, John Wiley \& Sons, Ltd., Chichester, 1st edn., 2018.

4 (a) S. K. Mellerup and S. Wang, Trends in Chemistry, 2019, 1, 77-89; (b) E. von Grotthuss, A. John, T. Kaese and M. Wagner, Asian J. Org. Chem., 2018, 7, 37-53; (c) M. Stępień, E. Gońka, M. Żyła and N. Sprutta, Chem. Rev., 2017, 117, 3479-3716; (d) L. Ji, S. Griesbeck and T. B. Marder, Chem. Sci., 2017, 8, 846863; (e) A. Escande and M. J. Ingleson, Chem. Commun., 2015, 51, 6257-6274; $(f)$ A. Wakamiya and S. Yamaguchi, Bull. Chem. Soc. Jpn., 2015, 88, 1357-1377; (g) A. Lorbach, A. Hübner and M. Wagner, Dalton Trans., 2012, 41, 60486063.

5 (a) A. John, S. Kirschner, M. K. Fengel, M. Bolte, H.-W. Lerner and M. Wagner, Dalton Trans., 2019, 48, 1871-1877; (b) S. Kirschner, J.-M. Mewes, M. Bolte, H.-W. Lerner, A. Dreuw and M. Wagner, Chem.-Eur. J., 2017, 23, 51045116; (c) A. John, M. Bolte, H.-W. Lerner and M. Wagner, Angew. Chem., Int. Ed., 2017, 56, 5588-5592; (d) C. Reus, S. Weidlich, M. Bolte, H.-W. Lerner and M. Wagner, J. Am. Chem. Soc., 2013, 135, 12892-12907; (e) A. Lorbach,
M. Bolte, H. Li, H.-W. Lerner, M. C. Holthausen, F. Jäkle and M. Wagner, Angew. Chem., Int. Ed., 2009, 48, 4584-4588.

6 D. L. Crossley, R. J. Kahan, S. Endres, A. J. Warner, R. A. Smith, J. Cid, J. J. Dunsford, J. E. Jones, I. VitoricaYrezabal and M. J. Ingleson, Chem. Sci., 2017, 8, 7969-7977. 7 J. M. Farrell, D. Schmidt, V. Grande and F. Würthner, Angew. Chem., Int. Ed., 2017, 56, 11846-11850.

8 J. M. Farrell, C. Mützel, D. Bialas, M. Rudolf, K. Menekse, A.-M. Krause, M. Stolte and F. Würthner, J. Am. Chem. Soc., 2019, 141, 9096-9104.

9 T. Kaehler, M. Bolte, H.-W. Lerner and M. Wagner, Angew. Chem., Int. Ed., 2019, 58, 11379-11384.

10 V. M. Hertz, M. Bolte, H.-W. Lerner and M. Wagner, Angew. Chem., Int. Ed., 2015, 54, 8800-8804.

11 C. Dou, S. Saito, K. Matsuo, I. Hisaki and S. Yamaguchi, Angew. Chem., Int. Ed., 2012, 51, 12206-12210.

12 P. Kovacic and M. B. Jones, Chem. Rev., 1987, 87, 357-379.

13 C. Hoffend, F. Schödel, M. Bolte, H.-W. Lerner and M. Wagner, Chem.-Eur. J., 2012, 18, 15394-15405.

14 C. Hoffend, M. Diefenbach, E. Januszewski, M. Bolte, H.-W. W. Lerner, M. C. Holthausen and M. Wagner, Dalton Trans., 2013, 42, 13826-13837.

15 B. T. King, J. Kroulík, C. R. Robertson, P. Rempala, C. L. Hilton, J. D. Korinek and L. M. Gortari, J. Org. Chem., 2007, 72, 2279-2288.

16 C. Dou, S. Saito and S. Yamaguchi, J. Am. Chem. Soc., 2013, 135, 9346-9349.

17 S. Osumi, S. Saito, C. Dou, K. Matsuo, K. Kume, H. Yoshikawa, K. Awaga and S. Yamaguchi, Chem. Sci., 2016, 7, 219-227.

18 K. Schickedanz, J. Radtke, M. Bolte, H.-W. Lerner and M. Wagner, J. Am. Chem. Soc., 2017, 139, 2842-2851.

19 Z. Zhou, A. Wakamiya, T. Kushida and S. Yamaguchi, J. Am. Chem. Soc., 2012, 134, 4529-4532.

20 S. Saito, K. Matsuo and S. Yamaguchi, J. Am. Chem. Soc., 2012, 134, 9130-9133.

21 Y. Shen and C.-F. Chen, Chem. Rev., 2012, 112, 1463-1535.

22 K. Schickedanz, T. Trageser, M. Bolte, H.-W. Lerner and M. Wagner, Chem. Commun., 2015, 51, 15808-15810.

23 V. M. Hertz, H.-W. Lerner and M. Wagner, Org. Lett., 2015, 17, 5240-5243.

24 V. M. Hertz, J. G. Massoth, M. Bolte, H.-W. Lerner and M. Wagner, Chem.-Eur. J., 2016, 22, 13181-13188.

25 T. Yamamoto, S. Wakabayashi and K. Osakada, J. Organomet. Chem., 1992, 428, 223-237.

26 T. Yamamoto, Bull. Chem. Soc. Jpn., 2010, 83, 431-455.

27 J. E. Anthony, Chem. Rev., 2006, 106, 5028-5048.

28 J. E. Anthony, A. Facchetti, M. Heeney, S. R. Marder and X. Zhan, Adv. Mater., 2010, 22, 3876-3892.

29 B. X. Mi, Z. Q. Gao, M. W. Liu, K. Y. Chan, H. L. Kwong, N. B. Wong, C. S. Lee, L. S. Hung and S. T. Lee, J. Mater. Chem., 2002, 12, 1307-1310.

30 M. M. Rauhut, B. G. Roberts, D. R. Maulding, W. Bergmark and R. Coleman, J. Org. Chem., 1975, 40, 330-335.

31 T. Asahi, M. Yudasaka, K. Nakanishi, S. Iwashima, J. Aoki, N. Sato and H. Inokuchi, Phys. Status Solidi, 1990, 122, K97-K100. 
32 S. Toguchi, A. Oda, H. Ishikawa, US 6747287 B1, 2004.

33 T. Fujiyama, Y. Toya, M. Nakatsuka, JP 2008098360, 2008.

34 N. Sato, H. Inokuchi, K. Seki, J. Aoki and S. Iwashima, J. Chem. Soc., Faraday Trans. 2, 1982, 78, 1929-1936.

35 R. S. Becker and W. E. Wentworth, J. Am. Chem. Soc., 1963, 85, 2210-2214.

36 C. L. Hilton, J. M. Crowfoot, P. Rempala and B. T. King, J. Am. Chem. Soc., 2008, 130, 13392-13399.

37 K. Sakai, S. Ohshima, A. Uchida, I. Oonishi, S. Fujisawa and U. Nagashima, J. Phys. Chem., 1995, 99, 5909-5913.

38 F. Miyamoto, S. Nakatsuka, K. Yamada, K. Nakayama and T. Hatakeyama, Org. Lett., 2015, 17, 6158-6161.

39 A. John, M. Bolte, H.-W. Lerner, G. Meng, S. Wang, T. Peng and M. Wagner, J. Mater. Chem. C, 2018, 6, 10881-10887.

40 S. Brend'amour, J. Gilmer, M. Bolte, H.-W. Lerner and M. Wagner, Chem.-Eur. J., 2018, 24, 16910-16918.

41 H. E. Katz, Organometallics, 1986, 5, 2308-2311.

42 R. Tsuji, K. Komatsu, Y. Inoue and K. Takeuchi, J. Org. Chem., 1992, 57, 636-641.

$432^{\mathbf{B r}, \mathbf{I}}$ crystallizes with two symmetry-independent molecules in the asymmetric unit. One of them (shown in Scheme 1 and discussed in the main text) adopts a syn-configuration, the other one is disordered with a syn:anti ratio of approximately $9: 1$. Given this background and the results of ${ }^{1} \mathrm{H}$-NMR spectroscopy, it is reasonable to assume that the syn-conformation is preferred over the anticonformation in $\mathbf{2}^{\mathbf{B r}, \mathbf{I}}$.

44 J. M. Birchall and R. N. Haszeldine, J. Chem. Soc., 1961, 37193727.

45 M. Schulte and F. P. Gabbaï, J. Organomet. Chem., 2002, 643644, 164-167.

46 E. C. Rüdiger, M. Porz, M. Schaffroth, F. Rominger and U. H. F. Bunz, Chem.-Eur. J., 2014, 20, 12725-12728.

47 T. Yamamoto, Prog. Polym. Sci., 1992, 17, 1153-1205.

48 M. Mantina, A. C. Chamberlin, R. Valero, C. J. Cramer and D. G. Truhlar, J. Phys. Chem. A, 2009, 113, 5806-5812.

49 S. Grimme and S. D. Peyerimhoff, Chem. Phys., 1996, 204, 411-417.

50 K. Kato, Y. Segawa and K. Itami, Synlett, 2019, 30, 370-377.

51 The absolute configuration (i.e., $M, M$ or $P, P$ ) could not be determined due to the absence of anomalous scatterers.

52 The so far most highly twisted PAH is a hexacene with an end-to-end twist of $184^{\circ}$ : R. G. Clevenger, B. Kumar,
E. M. Menuey and K. V. Kilway, Chem.-Eur. J., 2018, 24, 3113-3116.

53 R. A. Pascal, Chem. Rev., 2006, 106, 4809-4819.

54 A. Izuoka, K. Wakui, T. Fukuda, N. Sato and T. Sugawara, Acta Crystallogr., Sect. C: Cryst. Struct. Commun., 1992, 48, 900-902.

55 A. Lorbach, M. Bolte, H.-W. Lerner and M. Wagner, Chem. Commun., 2010, 46, 3592-3594.

56 Ö. Seven, S. Popp, M. Bolte, H.-W. Lerner and M. Wagner, Dalton Trans., 2014, 43, 8241-8253.

57 A. Das, A. Hübner, M. Weber, M. Bolte, H.-W. Lerner and M. Wagner, Chem. Commun., 2011, 47, 11339-11341.

58 In this particular case, the degree of distortion of the oxadiborepin ring is likely also influenced by extensive intermolecular $\mathrm{O}-\mathrm{H} \cdots \mathrm{O}$ hydrogen bonding.

59 Q. Yan, M. Yin, C. Chen and Y. Zhang, J. Org. Chem., 2018, 83, 9096-9102.

60 J. D. Hoefelmeyer and F. P. Gabbaï, Organometallics, 2002, 21, 982-985.

61 J. D. Hoefelmeyer, S. Solé and F. P. Gabbaï, Dalton Trans., 2004, 4, 1254-1258.

62 E. von Grotthuss, S. E. Prey, M. Bolte, H.-W. Lerner and M. Wagner, Angew. Chem., Int. Ed., 2018, 57, 16491-16495.

63 S. Kirschner, S.-S. Bao, M. K. Fengel, M. Bolte, H.-W. Lerner and M. Wagner, Org. Biomol. Chem., 2019, 17, 5060-5065.

64 B. M. Rosen, K. W. Quasdorf, D. A. Wilson, N. Zhang, A.-M. Resmerita, N. K. Garg and V. Percec, Chem. Rev., 2011, 111, 1346-1416.

65 M. F. Semmelhack, P. M. Helquist and L. D. Jones, J. Am. Chem. Soc., 1971, 93, 5908-5910.

66 T. T. Tsou and J. K. Kochi, J. Am. Chem. Soc., 1979, 101, 75477560.

67 T. T. Tsou and J. K. Kochi, J. Am. Chem. Soc., 1979, 101, 63196332.

68 E. C. Rüdiger, S. Koser, F. Rominger, J. Freudenberg and U. H. F. Bunz, Chem.-Eur. J., 2018, 24, 9919-9927.

69 A. F. Alahmadi, R. A. Lalancette and F. Jäkle, Macromol. Rapid Commun., 2018, 39, 1800456.

70 Y. Fu, K. Zhang, E. Dmitrieva, F. Liu, J. Ma, J. J. Weigand, A. A. Popov, R. Berger, W. Pisula, J. Liu and X. Feng, Org. Lett., 2019, 21, 1354-1358.

71 Even though unlikely, we cannot exclude THF as source of the $\mathrm{O}$ atom incorporated into ODBE. 